\title{
Structure and properties of molybdenum oxide nitrides as model systems for selective oxidation catalysts
}

\author{
Sven Kühn, Peter Schmidt-Zhang, Alexander HP Hahn, Manoup Huber, Martin Lerch and Thorsten Ressler ${ }^{*}$
}

\begin{abstract}
Molybdenum oxide nitride (denoted as $\mathrm{Mo}(\mathrm{O}, \mathrm{N})_{3}$ ) was obtained by ammonolysis of $\alpha-\mathrm{MoO}_{3}$ with gaseous ammonia. Electronic and geometric structure, reducibility, and conductivity of $\mathrm{Mo}(\mathrm{O}, \mathrm{N})_{3}$ were investigated by XRD, XAS, UV-Vis spectroscopy, and impedance measurements. Catalytic performance in selective propene oxidation was determined by online mass spectrometry und gas chromatography. Upon incorporation of nitrogen, $\mathrm{Mo}(\mathrm{O}, \mathrm{N})_{3}$ maintained the characteristic layer structure of $\alpha_{-1 \mathrm{MOO}_{3}}$. XRD analysis showed an increased structural disorder in the layers while nitrogen is removed from the lattice of $\mathrm{Mo}(\mathrm{O}, \mathrm{N})_{3}$ at temperatures above $\sim 600 \mathrm{~K}$. Compared to regular $\alpha-\mathrm{MoO}_{3}, \mathrm{Mo}(\mathrm{O}, \mathrm{N})_{3}$ exhibited a higher electronic and ionic conductivity and an onset of reduction in propene at lower temperatures. Surprisingly, $\alpha-\mathrm{MoO}_{3}$ and $\mathrm{Mo}(\mathrm{O}, \mathrm{N})_{3}$ exhibited no detectable differences in onset temperatures of propene oxidation and catalytic selectivity or activity. Apparently, the increased reducibility, oxygen mobility, and conductivity of $\mathrm{Mo}(\mathrm{O}, \mathrm{N})_{3}$ compared to $\alpha-\mathrm{MoO}_{3}$ had no effect on the catalytic behavior of the two catalysts. The results presented confirm the suitability of molybdenum oxide nitrides as model systems for studying bulk contributions to selective oxidation.
\end{abstract}

\section{Background}

Molybdenum oxides are active heterogeneous catalysts for selective oxidation of light alkanes and alkenes [1-6]. In addition to catalytic activity and long-term stability, improved selectivity and efficient use of raw materials become of increasing importance in industrial applications. In spite of intensive research, structure-reactivity correlations and knowledge about the catalytically active species remain scarce. Hence, new catalysts are developed by "trial and error" methods. Although this approach has been successful, it becomes increasingly apparent that new ways need to be explored to further advance the design of improved functional materials. Therefore, a deeper understanding of the correlations between structure, activity, and selectivity will serve as the foundation for a knowledge-based development of new and enhanced catalysts.

Selective oxidation of alkenes using molybdenum oxide catalysts is commonly believed to proceed

\footnotetext{
* Correspondence: thorsten.ressler@tu-berlin.de

Technische Universität Berlin, Institut für Chemie, Sekr. C2, Strasse des 17. Juni 135, D-10623 Berlin, Germany
}

according to a reduction-oxidation-mechanism $[1,4]$. In a first step the reactant partially reduces the metal oxide catalyst. Afterwards, the catalyst is re-oxidized by oxygen from the gas phase. Hence, lattice oxygen of the molybdenum oxide catalyst is suggested to selectively oxidize the alkene. Oxidation experiments using ${ }^{18} \mathrm{O}$ have verified that lattice oxygen of $\alpha-\mathrm{MoO}_{3}$ is involved in the catalytic process [7]. Accordingly, mobility of oxygen in the lattice of the oxide catalyst is expected to play an important role for catalyst activity and selectivity.

Conventional molybdenum based oxide catalysts consist of either binary molybdenum oxide system or mixed oxides with additional metal centers. Additional metals such as $\mathrm{W}, \mathrm{Nb}$, or V stabilize characteristic crystallographic structures which lead to oxidation catalysts with improved activity and selectivity $[8,9]$. However, the influence of structural variety and chemical complexity in the mixed oxide systems on catalytic performance is difficult to distinguish. In order to reduce this inherent complexity of mixed oxide catalysts, suitable model systems are sought. In particular with respect to elucidating the effect of oxygen mobility on catalytic performance it 
appears counterproductive to vary chemical composition and oxide lattice structure simultaneously. Hence, instead of modifying the cation lattice to affect oxygen mobility it seems more promising to directly modify the anion lattice. Ideally however, this modification should have little influence on the long-range order crystallographic structure of the catalyst.

Along that line, metal oxide nitrides appear to be suitable model systems. In many cases nitrogen can be incorporated in the oxide lattice of a particular metal oxide without changing the crystallographic structure $[10,11]$. Alternatively, metastable and previously not available oxide structures can be obtained without changing the cation composition $[12,13]$. Both approaches may result in suitable model systems for selective oxidation catalysts. Zirconium oxide nitrides, for instance, have been shown to be active catalysts for ammonia decomposition [14]. It is suggested, however, that in these materials the nitrogen atoms not only affect anion mobility but also directly participate in the catalytic reaction.

In this work we have chosen molybdenum trioxide in the orthorhombic $\alpha-\mathrm{MoO}_{3}$ modification as well-known model system for selective propene oxidation catalysts. $\alpha-\mathrm{MoO}_{3}$ is transformed into the corresponding molybdenum oxide nitride by reaction with gaseous ammonia. Subsequently, the thus obtained model catalyst is used to reveal correlations between lattice oxygen availability, electrical properties, and catalytic activity and selectivity in selective propene oxidation.

\section{Results and Discussion}

Structural characterization of $\mathrm{Mo}(\mathrm{O}, \mathrm{N})_{3}$

Geometric and electronic structure of $\mathrm{Mo}(\mathrm{O}, \mathrm{N})_{3}$ and reference $\alpha-\mathrm{MoO}_{3}$ were investigated by XRD, XAS, and DR-UV-Vis spectroscopy. The aim of these studies was to reveal significant differences in structural and electronic properties of the two materials to be used as model systems for oxidation catalysts. Interestingly, incorporation of nitrogen in $\alpha-\mathrm{MoO}_{3}$ resulted in a pronounced color change of the material. In contrast to the lightgrey color of $\alpha-\mathrm{MoO}_{3}, \mathrm{Mo}(\mathrm{O}, \mathrm{N})_{3}$ exhibited a dark-blue color. This color change, however, cannot be attributed to a significant reduction of $\mathrm{MoO}_{3}$ to $\mathrm{MoO}_{2}(<5 \%)$.

XRD patterns and XAS spectra of $\alpha-\mathrm{MoO}_{3}$ and $\mathrm{Mo}(\mathrm{O}$, $\mathrm{N})_{3}$ are shown in Figure 1 and Figure 2, respectively. The XRD pattern and the XANES and EXAFS spectra of $\mathrm{Mo}(\mathrm{O}, \mathrm{N})_{3}$ are similar to those of $\alpha-\mathrm{MoO}_{3}$ without additional phases detectable. Crystallite size of $\alpha-\mathrm{MoO}_{3}$ amounted to $\sim 60 \mathrm{~nm}$ as calculated from the integral breadths of XRD peaks using the Scherrer equation [15]. Apparently, the long-range order and short-range order structure of $\alpha-\mathrm{MoO}_{3}$ is preserved after incorporation of nitrogen. Despite the overall agreement, subtle differences can be seen in the XRD patterns and XAS data of $\alpha-\mathrm{MoO}_{3}$ and $\mathrm{Mo}(\mathrm{O}, \mathrm{N})_{3}$. An increased XRD peak broadening (Figure 1) and a reduced XAFS amplitude (Figure 2) indicate an increased formation of defects in the $\mathrm{Mo}(\mathrm{O}, \mathrm{N})_{3}$ structure upon nitridation. It is suggested that nitrogen atoms substitute for oxygen in the layers of $\alpha-\mathrm{MoO}_{3}$ leading to an increased strain and a corresponding peak broadening in the XRD pattern. Similarly, an increased distance distribution around the Mo centers in $\mathrm{Mo}(\mathrm{O}, \mathrm{N})_{3}$ resulted in the XAFS amplitude reduction observed. Moreover, analysis of the Mo K edge shift revealed an average valence of +5.86 for $\mathrm{Mo}(\mathrm{O}, \mathrm{N})_{3}$ and +5.96 for the $\alpha-\mathrm{MoO}_{3}$ used as reference [16]. According to the simplified defect model assumed incorporation of nitrogen results in formation of vacancies in the anion lattice $\left(3 \mathrm{O}_{\mathrm{O}}^{\mathrm{x}}+2 \mathrm{NH}_{3} \rightarrow 2 \mathrm{~N}_{\mathrm{O}}^{\prime}+\mathrm{V}_{\mathrm{O}}^{\circ}+3 \mathrm{H}_{2} \mathrm{O}\right)$. Therefore, the slight reduction in Mo average valence should not be related to the presence of nitrogen but rather originate from a slight reduction of $\alpha-\mathrm{MoO}_{3}$ by gaseous ammonia during sample preparation. However, the corresponding $5 \% \mathrm{MoO}_{2}$ were not detectable in the XRD or XAFS data of $\mathrm{Mo}(\mathrm{O}, \mathrm{N})_{3}$.

Absorption edge energies in the UV-Vis range as determined by DR-UV-Vis spectroscopy (Figure 1) amounted to $3.3 \mathrm{eV}$ for $\alpha-\mathrm{MoO}_{3}$ and $2.8 \mathrm{eV}$ for $\mathrm{Mo}(\mathrm{O}$, $\mathrm{N}_{3}$. Inter-valence transitions in the range from $1-3 \mathrm{eV}$ in the UV-Vis spectrum of $\alpha-\mathrm{MoO}_{3}$ corroborated the reduced average valence of 5.96 and the light-gray color of the reference $\alpha-\mathrm{MoO}_{3}$ [17]. The dark-blue color of $\mathrm{Mo}(\mathrm{O}, \mathrm{N})_{3}$ is suggested to originate from the formation of color centers accompanying the incorporation of nitrogen in the oxygen lattice. A similar effect has been described for intensely colored zirconium oxide nitrides compared to colorless $\mathrm{ZrO}_{2}$ [18].

\section{Thermal stability of $\mathrm{Mo}(\mathrm{O}, \mathrm{N})_{3}$}

After confirming that the long-range structure of $\alpha$ $\mathrm{MoO}_{3}$ persisted after incorporation of nitrogen, thermal stability of $\mathrm{Mo}(\mathrm{O}, \mathrm{N})_{3}$ was studied prior to aiming at correlations between oxygen mobility and catalytic properties. Therefore, in situ XRD patterns of $\mathrm{Mo}(\mathrm{O}, \mathrm{N})_{3}$ were measured under oxidative reaction conditions $\left(5 \% \mathrm{O}_{2}\right.$ in $\mathrm{He}$ ). Figure 3 shows the evolution of XRD patterns of $\mathrm{Mo}(\mathrm{O}, \mathrm{N})_{3}$ in the temperature range from $473 \mathrm{~K}$ to 773 $\mathrm{K}$. The XRD patterns of $\mathrm{Mo}(\mathrm{O}, \mathrm{N})_{3}$ exhibited an increasing peak intensity and decreasing peak-broadening with increasing reaction temperature. Conversely, the XRD patterns of $\alpha-\mathrm{MoO}_{3}$ showed no significant changes during thermal treatment in oxygen. For a more detailed analysis, evolution of the integral breadth determined from the 110, 101, and 020 reflections of $\alpha-\mathrm{MoO}_{3}$ and $\mathrm{Mo}(\mathrm{O}, \mathrm{N})_{3}$ is shown in Figure 3. Only minor changes were detectable for $\alpha-\mathrm{MoO}_{3}$. Conversely, above $\sim 623 \mathrm{~K}$ the integral breadth determined for $\mathrm{Mo}(\mathrm{O}, \mathrm{N})_{3}$ changed 

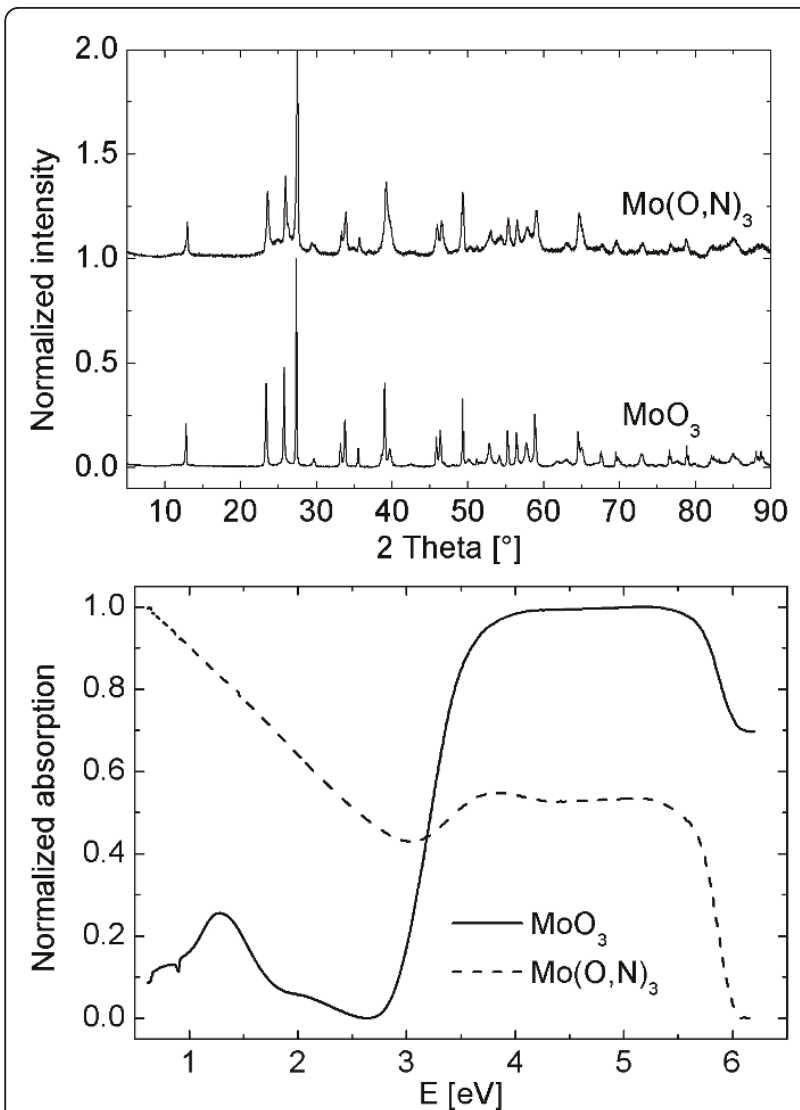

Figure 1 XRD patterns (top) and DR-UV-Vis absorption spectra (bottom) of $\alpha-\mathrm{MoO}_{3}$ and $\mathrm{Mo}(\mathrm{O}, \mathrm{N})_{3}$.

dramatically while the effect decreased going from 020 to 110 and 101. Variations in integral breadth can be attributed to changes in crystallite size, strain, or disorder. Because of the characteristic evolution of integral breadth with temperature as depicted in Figure 3 the changes observed were interpreted in terms of varying disorder in the crystallites of $\mathrm{Mo}(\mathrm{O}, \mathrm{N})_{3}$. Apparently, at temperatures above $\sim 623 \mathrm{~K}$ nitrogen was removed from the molybdenum oxide lattice. This was accompanied by a reduced defect density in the layers of $\mathrm{Mo}(\mathrm{O}, \mathrm{N})_{3}$ which corresponds to the more pronounced change in peak-width of the 020 peak compared to 110 or 101 (Figure 3). Above $700 \mathrm{~K}$ the integral breadths of thermally treated $\mathrm{Mo}(\mathrm{O}, \mathrm{N})_{3}$ became similar to those of $\alpha$ $\mathrm{MoO}_{3}$. This indicates the largely reversible incorporation and removal of nitrogen from the oxide layer structure of $\alpha-\mathrm{MoO}_{3}$. Furthermore, evolution of DR-UV-Vis spectra of $\mathrm{Mo}(\mathrm{O}, \mathrm{N})_{3}$ during thermal treatment in oxygen revealed an increase of the absorption edge energy above $\sim 623 \mathrm{~K}$. Again the final edge energy above $700 \mathrm{~K}$ corresponded to that of $\alpha-\mathrm{MoO}_{3}$. Eventually, $\mathrm{Mo}(\mathrm{O}, \mathrm{N})_{3}$ samples subjected to thermal treatment at $673 \mathrm{~K}$ in various in situ experiments exhibited a remaining nitrogen
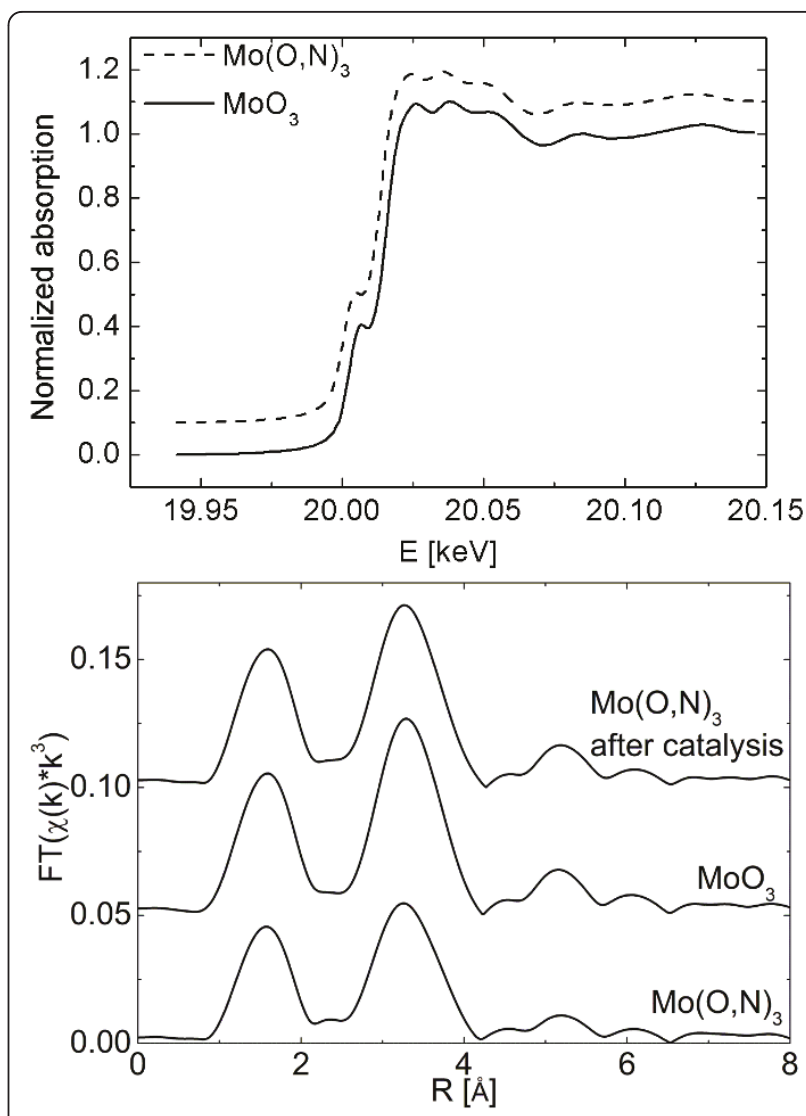

Figure 2 XANES spectra of $\alpha-\mathrm{MoO}_{3}$ and $\mathrm{Mo}(\mathrm{O}, \mathrm{N})_{3}$ at $298 \mathrm{~K}$ (top) and Fourier transformed $\chi(\mathrm{k})$ of $\alpha-\mathrm{MoO}_{3}$ and $\mathrm{Mo}(\mathrm{O}, \mathrm{N})_{3}$ (before and after catalysis) (bottom).

content of about $25 \%$ of the original amount. Hence, it was concluded that $\mathrm{Mo}(\mathrm{O}, \mathrm{N})_{3}$ constitutes a suitable model system for correlating structural and functional properties of an anion-lattice modified Mo oxide catalyst at temperatures below $673 \mathrm{~K}$.

\section{Reducibility of $\alpha-\mathrm{MoO}_{3}$ and $\mathrm{Mo}(\mathrm{O}, \mathrm{N})_{3}$}

According to the redox mechanism for selective oxidation reactions, availability of lattice oxygen to the gaseous reactants appears to be an important parameter for activity and selectivity of oxidation catalysts. Hence, temperature-programmed reduction is a common method to investigate and compare metal oxide catalysts. Here, the reduction behavior of $\alpha-\mathrm{MoO}_{3}$ and Mo $(\mathrm{O}, \mathrm{N})_{3}$ was studied in situ by XRD, XAS, and DR-UV$V$ is spectroscopy. As reported previously, $\alpha-\mathrm{MoO}_{3}$ is readily reduced to $\mathrm{MoO}_{2}$ in $5 \%$ propene at temperatures above $\sim 650 \mathrm{~K}[16,19-21]$. Besides the formation of shear-structural defects in the $\alpha-\mathrm{MoO}_{3}$ layers, no ordered intermediate phases are detectable during reduction. Similar to these previous reports reduction of both $\mathrm{Mo}(\mathrm{O}, \mathrm{N})_{3}$ and $\alpha-\mathrm{MoO}_{3}$ to $\mathrm{MoO}_{2}$ was observed by 


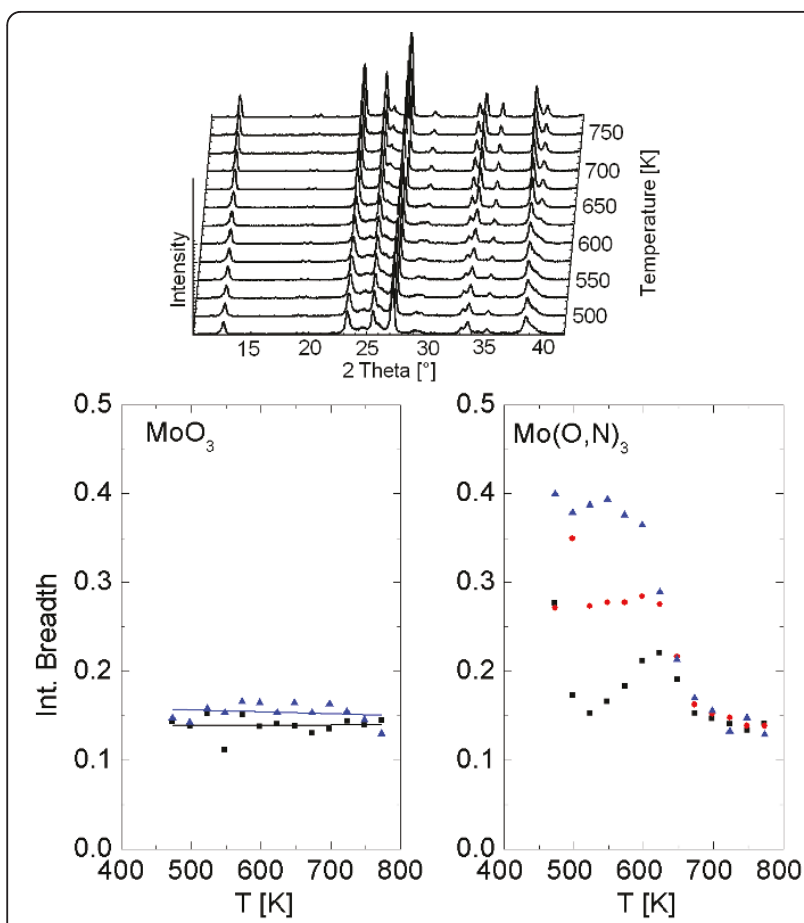

Figure 3 Evolution of XRD patterns during thermal treatment of $\mathrm{Mo}(\mathrm{O}, \mathrm{N})_{3}\left(473-773 \mathrm{~K}, 5 \% \mathrm{O}_{2}\right.$ in $\left.\mathrm{He}\right)$ and integral breadth calculated for reflections 020 (rectangles), 110 (circles), and 101 (triangles) of $\alpha-\mathrm{MoO}_{3}$ and $\mathrm{Mo}(\mathrm{O}, \mathrm{N})_{3}$.

in situ XRD and XAS. However, analysis of Mo K edge position and evolution of gaseous products revealed a much improved reducibility of $\mathrm{Mo}(\mathrm{O}, \mathrm{N})_{3}$ (Figure 4). Apparently, the presence of nitrogen in the $\alpha-\mathrm{MoO}_{3}$ layers resulted in an onset temperature of $\sim 660 \mathrm{~K}$ for $\mathrm{Mo}(\mathrm{O}, \mathrm{N})_{3}$ compared to $\sim 700 \mathrm{~K}$ for $\alpha-\mathrm{MoO}_{3}$. Given the nearly identical long-range order structures, crystallite sizes, and morphologies of $\alpha-\mathrm{MoO}_{3}$ and $\mathrm{Mo}(\mathrm{O}, \mathrm{N})_{3}$, the better reducibility of $\mathrm{Mo}(\mathrm{O}, \mathrm{N})_{3}$ has to be attributed to an increased oxygen mobility in the defect-rich layers of $\mathrm{Mo}(\mathrm{O}, \mathrm{N})_{3}$. The higher oxygen mobility of $\mathrm{Mo}(\mathrm{O}, \mathrm{N})_{3}$ compared to $\alpha-\mathrm{MoO}_{3}$ may be caused by oxygen vacancies formed during incorporation of nitrogen in $\alpha$ $\mathrm{MoO}_{3}$ according to $3 \mathrm{O}_{\mathrm{O}}^{\mathrm{x}}+2 \mathrm{NH}_{3} \rightarrow 2 \mathrm{~N}_{\mathrm{O}}^{\prime}+\mathrm{V}_{\mathrm{O}}^{\circ 0}+3 \mathrm{H}_{2} \mathrm{O}$. Eventually, the treatment of $\mathrm{Mo}(\mathrm{O}, \mathrm{N})_{3}$ at temperatures above $750 \mathrm{~K}$ resulted in the removal of nitrogen from the oxide layers. Upon re-oxidation to $\mathrm{MoO}_{3}$ both materials exhibited the same reduction behavior.

\section{Electrical properties of $\mathrm{Mo}(\mathrm{O}, \mathrm{N})_{3}$}

Incorporation of nitrogen in the layer structure of $\alpha$ $\mathrm{MoO}_{3}$ should have a pronounced effect on the electrical properties of $\mathrm{Mo}(\mathrm{O}, \mathrm{N})_{3}$ (i.e. both electronic and ionic conductivity). Conductivity of $\alpha-\mathrm{MoO}_{3}$ and $\mathrm{Mo}(\mathrm{O}, \mathrm{N})_{3}$ was studied by impedance spectroscopy. At $300 \mathrm{~K}$ the conductivity of $\mathrm{Mo}(\mathrm{O}, \mathrm{N})_{3}$ exceeded that of $\alpha-\mathrm{MoO}_{3}$ by

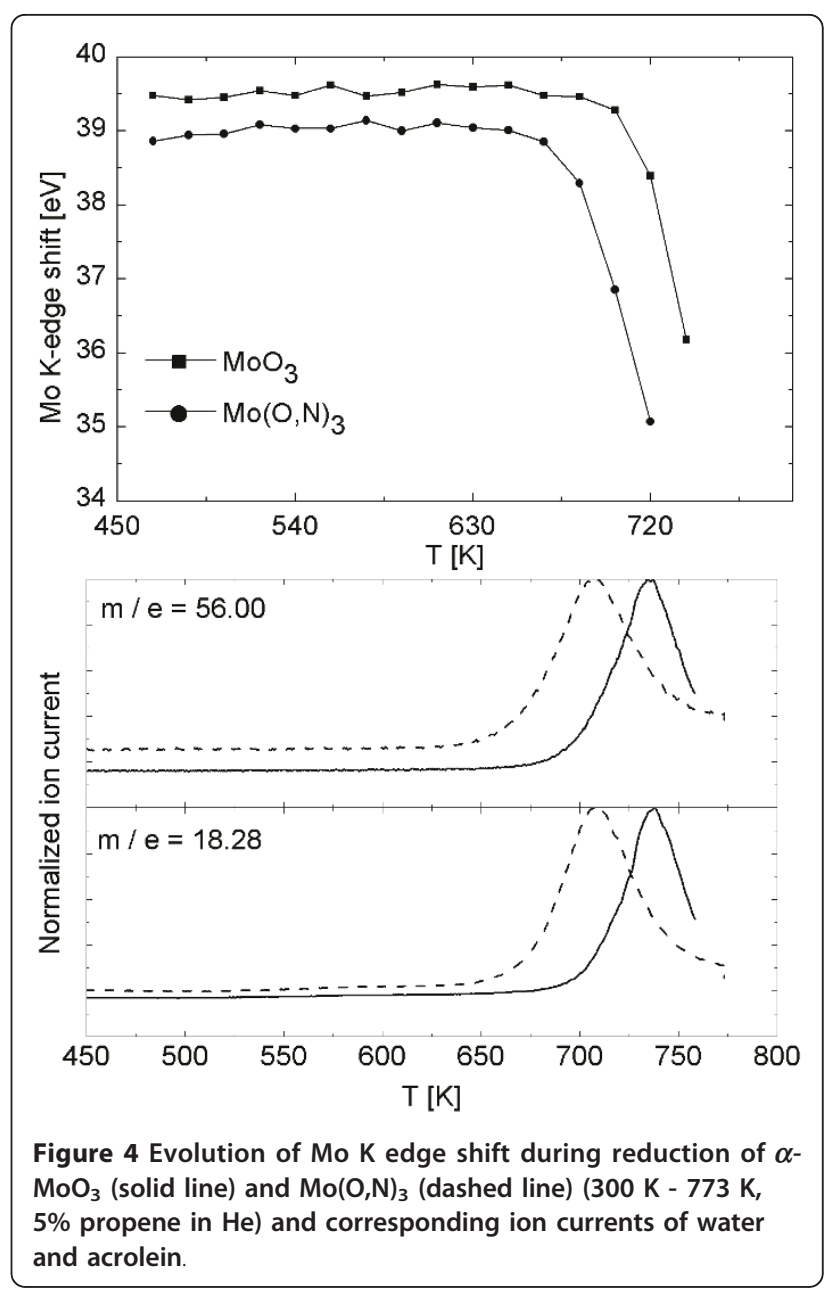

a factor of 500. Unfortunately, the set-up used did not permit to distinguish between electronic and ionic conductivity in a mixed conductor such as $\alpha-\mathrm{MoO}_{3}$. Hence, the dominating conduction process at a given temperature was concluded from the corresponding activation energy obtained from temperature-dependent impedance measurements. As an example, Figure 5 shows the Nyquist presentation of impedance measurements of $\alpha-\mathrm{MoO}_{3}$ in the temperature range from $524 \mathrm{~K}$ to $834 \mathrm{~K}$. The decreasing diameter of the semi-circles corresponds to a decreasing resistance with increasing temperature. Evolution of the resistance of $\mathrm{Mo}(\mathrm{O}, \mathrm{N})_{3}$ during thermal treatment in air is shown in Figure 5 . Above $600 \mathrm{~K} \mathrm{Mo}$ $(\mathrm{O}, \mathrm{N})_{3}$ exhibited an increasing resistance. Eventually, at temperatures above $700 \mathrm{~K}$ the thermally treated $\mathrm{Mo}(\mathrm{O}$, $\mathrm{N})_{3}$ showed the same resistance as $\alpha-\mathrm{MoO}_{3}$. This temperature range coincides with the onset of oxygen mobility above $600 \mathrm{~K}$ and the removal of nitrogen from Mo $(\mathrm{O}, \mathrm{N})_{3}$ between $600 \mathrm{~K}$ and $700 \mathrm{~K}$ followed by formation of regular $\alpha-\mathrm{MoO}_{3}$. Hence, the evolution of electrical properties of $\mathrm{Mo}(\mathrm{O}, \mathrm{N})_{3}$ is in good agreement with the 

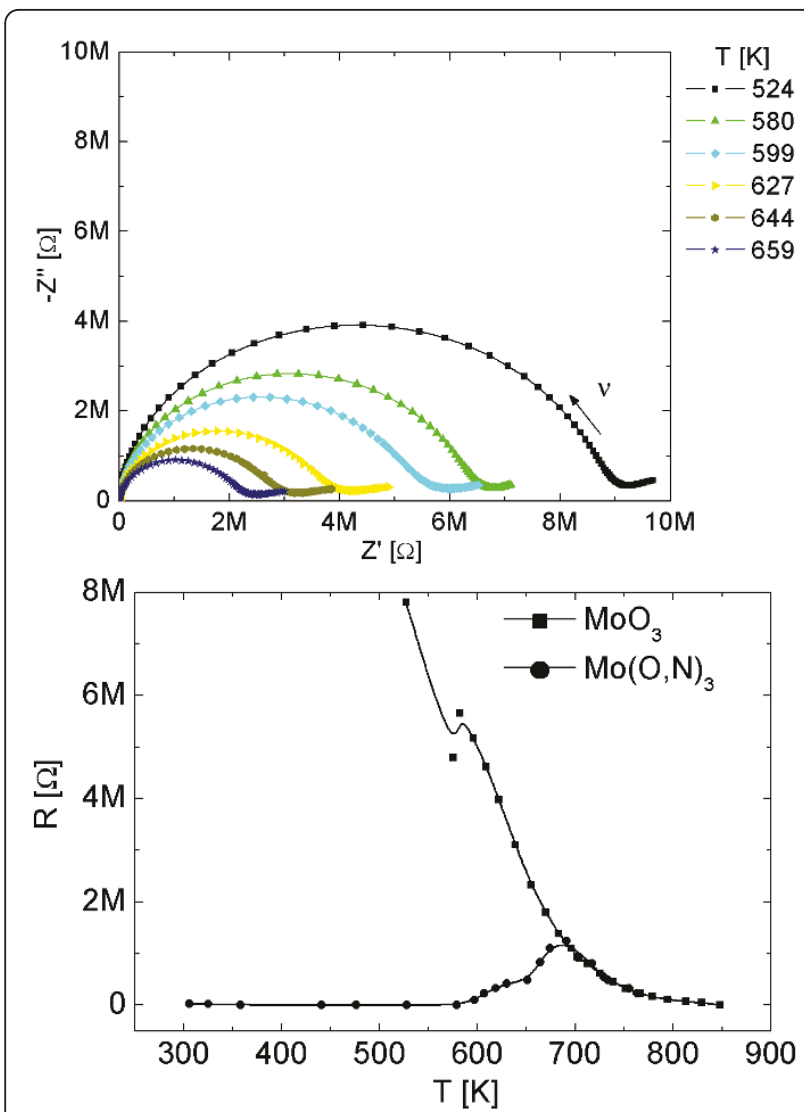

Figure 5 Nyquist presentation of impedance measurements of $\alpha-\mathrm{MoO}_{3}$ (top) at selected temperatures between $524 \mathrm{~K}$ and $659 \mathrm{~K}$ and evolution of resistances of $\alpha-\mathrm{MoO}_{3}$ and $\mathrm{Mo}(\mathrm{O}, \mathrm{N})_{3}$ with increasing temperature (bottom).

structural changes occurring between $600 \mathrm{~K}$ and $700 \mathrm{~K}$ (Figure 3).

From an Arrhenius type presentation of the conductivity as a function of temperature, the activation energies of the corresponding dominating processes can be obtained. $\alpha-\mathrm{MoO}_{3}$ showed two different extrinsic conduction processes with activation energies of $0.22 \mathrm{eV}$ and $0.77 \mathrm{eV}$ below $773 \mathrm{~K}$ (Figure 6). These values agree with previous reports [22] and have been assigned to electronic and structural defects in $\alpha-\mathrm{MoO}_{3}(0.22 \mathrm{eV})$ and oxygen mobility at temperatures above $639 \mathrm{~K}(0.77$ $\mathrm{eV})$. Above $773 \mathrm{~K}$ an activation energy of $1.56 \mathrm{eV}$ was found. With respect to the band gap energy of $\alpha-\mathrm{MoO}_{3}$ of $3.3 \mathrm{eV}$, this activation energy is assigned to intrinsic conduction of $\mathrm{MoO}_{3}$. At temperatures below $500 \mathrm{~K} \mathrm{Mo}$ $(\mathrm{O}, \mathrm{N})_{3}$ showed two activation energies of different extrinsic conduction processes (Figure 6). Because of the beginning and rather continuous reaction of $\mathrm{Mo}(\mathrm{O}, \mathrm{N})_{3}$ to $\alpha-\mathrm{MoO}_{3}$ at temperatures above $500 \mathrm{~K}$, no reliable activation energies could be obtained in this temperature range.

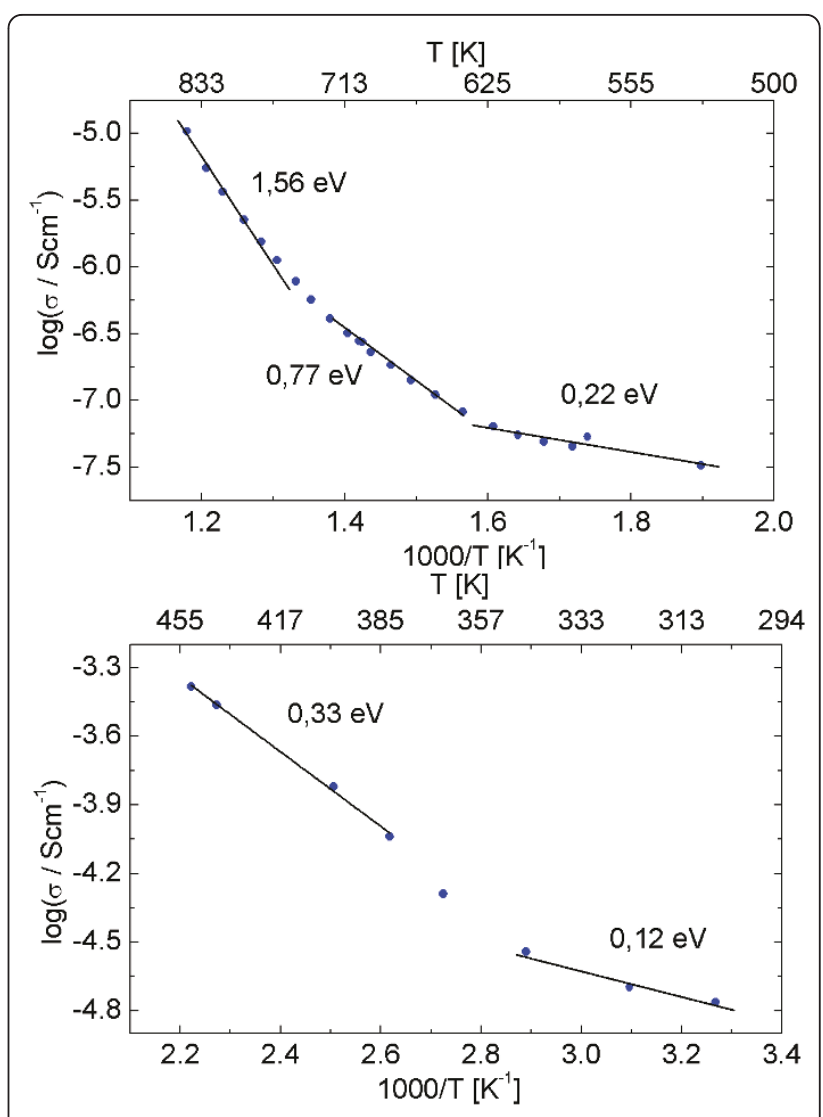

Figure 6 Arrhenius type presentation of conductivity of $\alpha$ $\mathrm{MoO}_{3}$ (top) and $\mathrm{Mo}(\mathrm{O}, \mathrm{N})_{3}$ (bottom). Activation energies of various conduction processes are indicated.

Functional and structural characterization of $\mathrm{Mo}(\mathrm{O}, \mathrm{N})_{3}$ under catalytic conditions

Functional characterization of $\mathrm{Mo}(\mathrm{O}, \mathrm{N})_{3}$ and $\alpha-\mathrm{MoO}_{3}$ in selective propene oxidation was conducted simultaneously with in situ structural UV-Vis and XAS measurements. For a sufficient time-resolution, the gas phase composition was qualitatively analyzed by a noncalibrated mass spectrometer. Time-resolved measurements were required because of the ongoing nitrogen removal from $\mathrm{Mo}(\mathrm{O}, \mathrm{N})_{3}$ at temperatures above $600 \mathrm{~K}$. Prolonged experiments under steady-state conditions may have been prone to missing minor differences in the performance of the catalysts. Repeated quantitative measurements of the gas phase composition under selective oxidation reaction conditions were performed by gas chromatography at selected temperatures.

Evolution of Mo K edge Fourier transformed $\chi(\mathrm{k})$ of $\alpha-\mathrm{MoO}_{3}$ and $\mathrm{Mo}(\mathrm{O}, \mathrm{N})_{3}$ measured during thermal treatment in $5 \%$ propene and $5 \%$ oxygen in the temperature range from $300 \mathrm{~K}$ to $723 \mathrm{~K}$ is depicted in Figure 7. In the first run, besides minor differences in the spectra of the starting materials, $\alpha-\mathrm{MoO}_{3}$ and $\mathrm{Mo}(\mathrm{O}, \mathrm{N})_{3}$ exhibited 


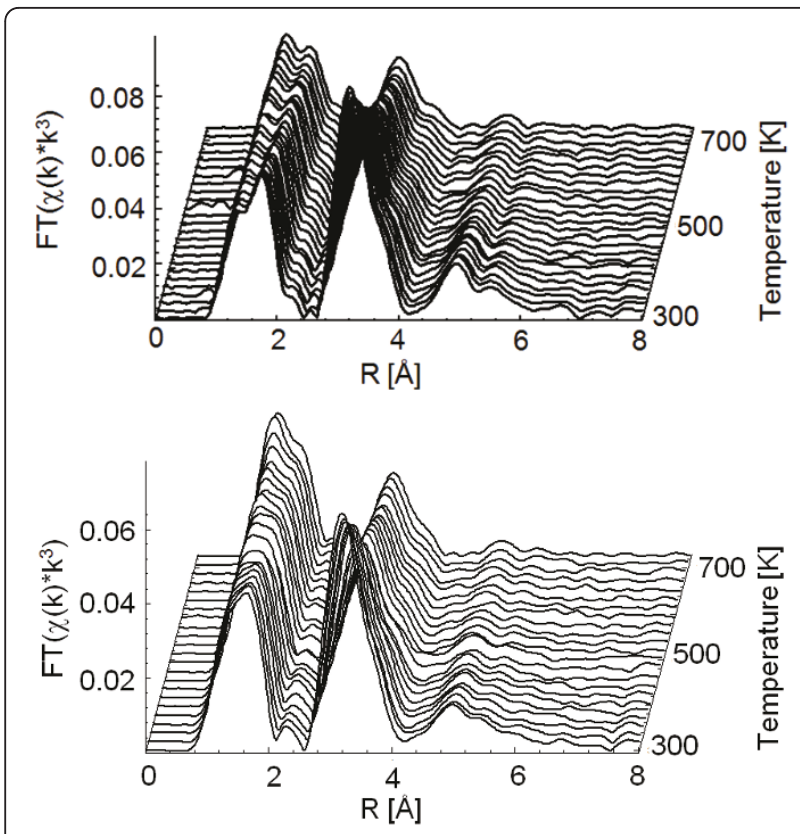

Figure 7 Evolution of Fourier transformed $\chi(\mathrm{k})$ of $\alpha-\mathrm{MoO}_{3}$ (top) and $\mathrm{Mo}(\mathrm{O}, \mathrm{N})_{3}$ (bottom) during treatment in $5 \%$ propene and $5 \%$ oxygen in the temperature range from $300 \mathrm{~K}$ to $723 \mathrm{~K}$

a similar evolution. The reduction in amplitude was mainly caused by the increasing reaction temperature. During a second thermal treatment under reaction conditions and, hence, after removal of nitrogen above 600 $\mathrm{K}$, both samples showed the same structural evolution. Moreover, the Mo K edge position of $\alpha-\mathrm{MoO}_{3}$ showed no significant change during treatment in propene and oxygen. Conversely, above $\sim 600 \mathrm{~K}$ the Mo K edge position of $\mathrm{Mo}(\mathrm{O}, \mathrm{N})_{3}$ continuously shifted to higher energies with increasing temperature. This behavior is again correlated to the removal of nitrogen at temperatures above $\sim 600 \mathrm{~K}$. During the second run the edge position remained at a constant value, similar to that of $\alpha$ $\mathrm{MoO}_{3}$. Hence, evolution of the local geometric and electronic structure revealed that removal of nitrogen from $\mathrm{Mo}(\mathrm{O}, \mathrm{N})_{3}$ under propene oxidation conditions resulted in regular $\alpha-\mathrm{MoO}_{3}$ exhibiting the same structural and electronic properties as the starting $\alpha-\mathrm{MoO}_{3}$ material. This is in good agreement with the in situ XRD measurements described above (Figure 3).

As to the catalytic properties of $\alpha-\mathrm{MoO}_{3}$ and $\mathrm{Mo}(\mathrm{O}$, $\mathrm{N})_{3}$, evolution of propene oxidation products acrolein and $\mathrm{CO}_{2}$ during two consecutive treatments is depicted in Figure 8. Apparently, under propene oxidation conditions both materials exhibited a very similar behavior already during the first treatment. Thus, no significant differences in onset temperature or product evolution were detectable. In spite of their significantly different structural and electronic characteristics (reducibility and conductivity) both sample showed a nearly identical catalytic performance.

In situ DR-UV-Vis experiments under propene oxidation conditions were performed in a temperature range from $298 \mathrm{~K}$ to $700 \mathrm{~K}$ during two consecutive runs. Evolution of DR-UV-Vis spectra of $\alpha-\mathrm{MoO}_{3}$ and $\mathrm{Mo}(\mathrm{O}, \mathrm{N})_{3}$ is depicted in Figure 9. Above $4 \mathrm{eV}$ the two series exhibited a very similar behavior. This corresponded to only

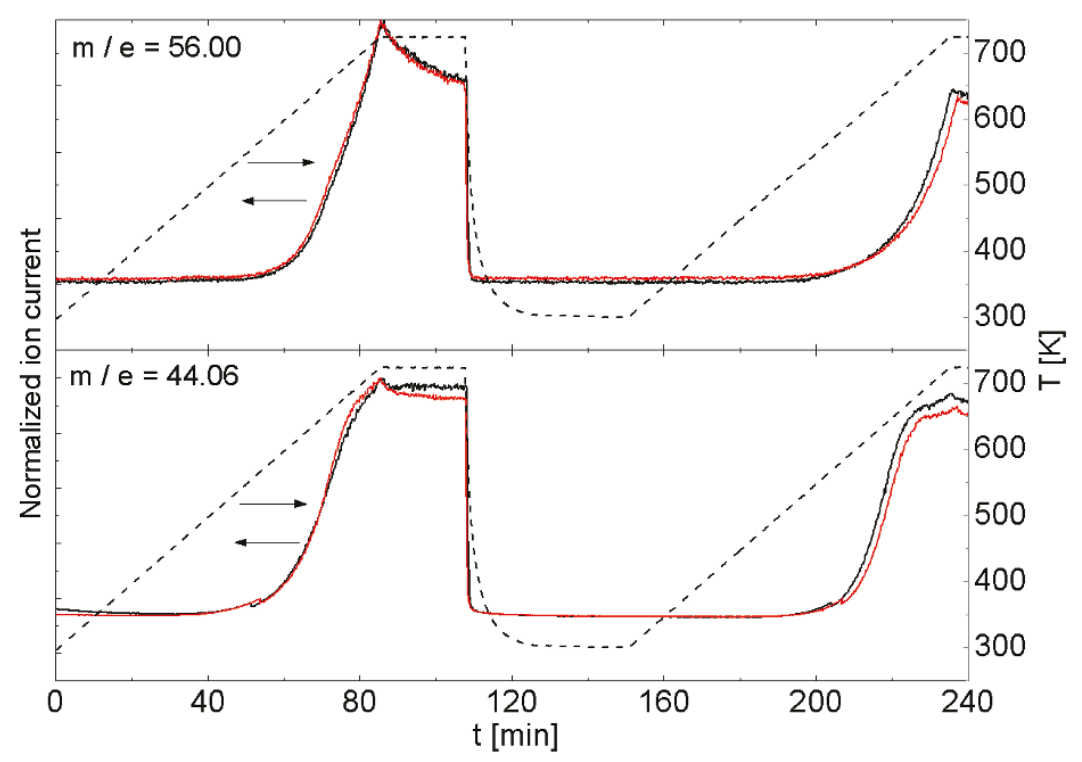

Figure 8 lon currents $\left(\mathrm{CO}_{2}\right.$ and acrolein) measured during in situ XAFS studies on $\alpha-\mathrm{MoO}_{3}$ (red) and $\mathrm{Mo}(\mathrm{O}, \mathrm{N})_{3}$ (black) (Figure 7$)$ in $5 \%$ propene and $5 \%$ oxygen in the temperature range from $300 \mathrm{~K}$ to $723 \mathrm{~K}$. 

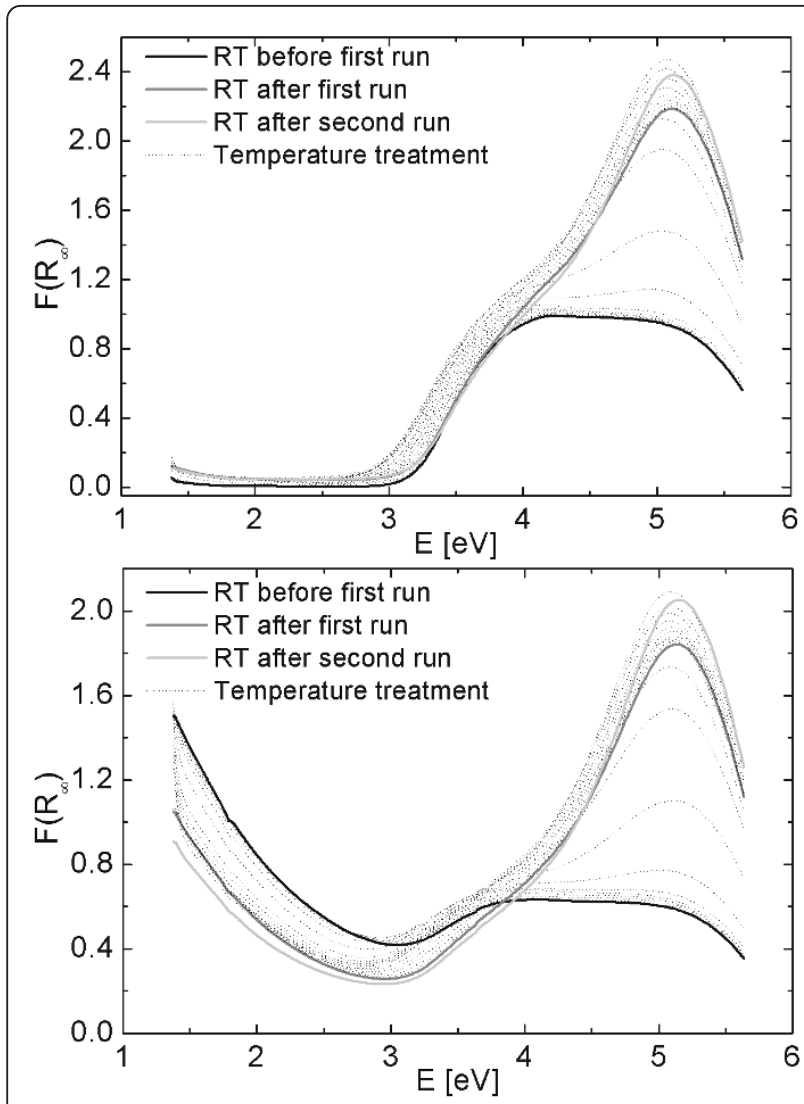

Figure 9 In situ DR-UV-Vis absorption spectra of $\alpha-\mathrm{MoO}_{3}$ and $\mathrm{Mo}(\mathrm{O}, \mathrm{N})_{3}$ measured during two consecutive treatments in $5 \%$ propene and $5 \% \mathrm{O}_{2}$ in the temperature range from $300 \mathrm{~K}$ to $700 \mathrm{~K}$.

minor structural changes in both $\mathrm{MoO}_{3}$ type materials under catalytic reaction conditions. Conversely, below the absorption edge at about $3.5 \mathrm{eV} \mathrm{Mo}(\mathrm{O}, \mathrm{N})_{3}$ showed a more pronounced change in the DR-UV-Vis spectra with temperature. This change corresponded to the removal of nitrogen at temperatures above $\sim 600 \mathrm{~K}$ and the accompanying modification of the electronic structure of $\mathrm{Mo}(\mathrm{O}, \mathrm{N})_{3}$. Accordingly, the UV-Vis spectrum of $\mathrm{Mo}(\mathrm{O}, \mathrm{N})_{3}$ after thermal treatment became more similar to that of regular $\alpha-\mathrm{MoO}_{3}$. The apparent differences between the spectra of both catalysts after thermal treatment can be ascribed to a residual amount of nitrogen in the oxygen lattice of $\mathrm{Mo}(\mathrm{O}, \mathrm{N})_{3}$. Overall, the structural changes observed in the evolution of UV-Vis spectra (Figure 9) were similar to the results of in situ XAS or XRD experiments as described above (Figure 3 and Figure 7). Apparently, in situ bulk structural studies on $\mathrm{Mo}(\mathrm{O}, \mathrm{N})_{3}$ and $\alpha-\mathrm{MoO}_{3}$ resulted in nearly the same short-range to medium-range structure after catalysis experiments. Conversely, UV-Vis spectroscopy proved to be more sensitive to minor electronic effects of nitrogen residuals in $\mathrm{Mo}(\mathrm{O}, \mathrm{N})_{3}$ after thermal treatment.
The corresponding evolution of MS ion currents of acrolein and $\mathrm{CO}_{2}$ measured during treatment of $\alpha-$ $\mathrm{MoO}_{3}$ and $\mathrm{Mo}(\mathrm{O}, \mathrm{N})_{3}$ in propene and oxygen from 300 $\mathrm{K}$ to $700 \mathrm{~K}$ is depicted in Figure 10. Apparently, during two consecutive treatments both catalysts exhibited the same onset of catalytic activity and the same qualitative evolution of catalytic performance. As stated above, no effect of the pronounced geometric and electronic differences between $\alpha-\mathrm{MoO}_{3}$ and $\mathrm{Mo}(\mathrm{O}, \mathrm{N})_{3}$ was detectable in the evolution of gaseous oxidation products during catalytic testing. The presence of nitrogen in $\mathrm{Mo}(\mathrm{O}, \mathrm{N})_{3}$ and the removal of a large fraction of nitrogen from Mo $(\mathrm{O}, \mathrm{N})_{3}$ during treatment at temperatures above $\sim 600 \mathrm{~K}$ did not result in detectable differences in catalytic behavior.

In addition to time-resolved MS measurement during catalytic testing, the gas phase composition at selected temperatures was quantitatively analyzed by gas chromatography. Conversion of propene and product selectivity to acrolein, $\mathrm{CO}_{2}$, and $\mathrm{CO}$ at $655 \mathrm{~K}$ and $700 \mathrm{~K}$ of $\alpha-\mathrm{MoO}_{3}$ and $\mathrm{Mo}(\mathrm{O}, \mathrm{N})_{3}$ are shown in Figure 11. Under the reaction conditions chosen, $\alpha-\mathrm{MoO}_{3}$ and $\mathrm{Mo}(\mathrm{O}, \mathrm{N})_{3}$ exhibited an average propene conversion of $1.1 \%$ or $2.2 \%$, and $1.1 \%$ or $2.5 \%$, respectively. Additionally, $\alpha-$ $\mathrm{MoO}_{3}$ and $\mathrm{Mo}(\mathrm{O}, \mathrm{N})_{3}$ exhibited nearly the same product selectivities at the reaction temperatures used. As already observed in the time-resolved measurements, also under steady-state conditions the presence of nitrogen in $\mathrm{Mo}(\mathrm{O}, \mathrm{N})_{3}$ did not result in significant differences in catalytic behavior compared to $\alpha-\mathrm{MoO}_{3}$.

\section{Conclusions}

Eventually, structure function correlations of $\mathrm{Mo}(\mathrm{O}, \mathrm{N})_{3}$ can be concluded from the described investigations. Characterization of electronic and geometric structure as well as reducibility of $\mathrm{Mo}(\mathrm{O}, \mathrm{N})_{3}$ resulted in a pronounced influence of the incorporation of nitrogen in the layer structure of $\alpha-\mathrm{MoO}_{3}$ (Figure 1 - Figure 4). Compared to regular $\alpha-\mathrm{MoO}_{3}, \mathrm{Mo}(\mathrm{O}, \mathrm{N})_{3}$ exhibited a much increased electronic and ionic conductivity (Figure 5). The latter afforded a lowering of the onset of reduction of $\mathrm{Mo}(\mathrm{O}, \mathrm{N})_{3}$ by about $40 \mathrm{~K}$ (Figure 4). Structural studies at elevated temperatures showed that nitrogen is removed from the oxide lattice of $\mathrm{Mo}(\mathrm{O}, \mathrm{N})_{3}$ above $\sim 600$ $\mathrm{K}$. The thus obtained $\mathrm{MoO}_{3}$ exhibited again the same short-range and long-range structural characteristics as the parent $\alpha-\mathrm{MoO}_{3}$ material (Figure 3 and Figure 7). Nevertheless, in spite of these characteristic differences between the $\alpha-\mathrm{MoO}_{3}$ and $\mathrm{Mo}(\mathrm{O}, \mathrm{N})_{3}$ used, both materials exhibited no detectable differences in their catalytic behavior. Neither studying onset temperatures by timeresolved methods (Figure 8 and Figure 10) nor measuring conversion or selectivity under steady-state conditions (Figure 11) revealed a pronounced influence of the 


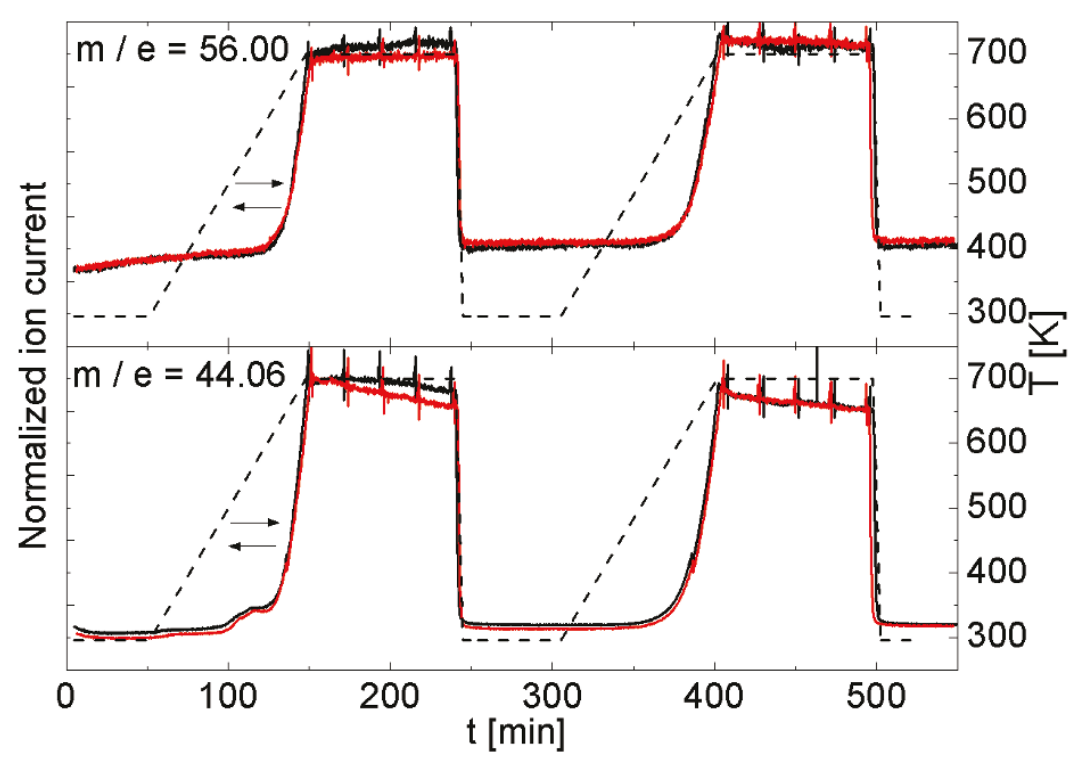

Figure 10 lon currents $\left(\mathrm{CO}_{2}\right.$ and acrolein) measured during two consecutive treatments of $\alpha-\mathrm{MoO}_{3}$ (red) and $\mathrm{Mo}(\mathrm{O}, \mathrm{N})_{3}$ (black) (Figure 9) in $5 \%$ propene and $5 \%$ oxygen in the temperature range from $300 \mathrm{~K}$ to $700 \mathrm{~K}$.

incorporation of nitrogen in the oxide lattice on catalytic properties.

In the conventional reduction-oxidation mechanism for selective oxidation reactions the reactant is oxidized by nucleophilic lattice oxygen. This way, oxygen vacancies in the oxide lattice are generated at the surface of the catalyst. Subsequently, these vacancies are supposed to be re-filled by diffusion of oxygen from the bulk of the oxide catalyst to its surface. Desorption of products terminates the catalytic cycle and frees the active site for the next reactant molecule. Eventually, the catalyst needs to be re-oxidized by gas phase oxygen to prevent deep-reduction and deactivation. However, if in fact diffusion of oxygen was required to replenish the oxygen reservoir at the catalyst surface, influencing the mobility of oxygen in the catalyst bulk structure should have a distinct influence on its catalytic properties. The results presented here suggest that at least for $\alpha-\mathrm{MoO}_{3}$ in propene oxidation this is not the case. Apparently, varying oxygen mobility has no detectable effect on the catalytic performance of $\alpha-\mathrm{MoO}_{3}$. This implies that if oxygen vacancies are generated at the surface of the catalyst by reaction with propene, these vacancies will be directly filled by gas phase reaction without requiring diffusion of oxygen from the bulk. Hence, the similar catalytic behavior of $\alpha-\mathrm{MoO}_{3}$ and $\mathrm{Mo}(\mathrm{O}, \mathrm{N})_{3}$ may be attributed to similar surface structures forming on both materials under reaction conditions. This may underline the importance of the particular structure and composition of the surface rather than optimized bulk properties of selective oxidation catalysts. However, the bulk structural characterization techniques employed here do not permit further conclusions as to the surface structures of the materials. Moreover, whether activation and oxidation of propene, and activation of gas phase oxygen occur simultaneously or in consecutive steps can only be speculated. However, it appears that a conventional Langmuir-Hinshelwood type mechanism may sufficiently describe propene oxidation on $\alpha-\mathrm{MoO}_{3}$ without requiring a particular contribution from the catalyst bulk.

In summary, the results presented here confirm the suitability of molybdenum oxide nitrides as model systems for studying bulk contributions to selective alkene oxidation. With regular $\alpha-\mathrm{MoO}_{3}$, incorporation of nitrogen permits to significantly and reversibly modify electronic properties and bulk oxygen mobility. Nitrogen can be conveniently removed from the oxide lattice by thermal treatment resulting in the original starting material. Hence, catalytic properties of the materials with and without nitrogen in the oxide lattice can readily be probed by consecutive experiments. Future studies on mixed molybdenum oxide nitrides will be employed to confirm both their applicability as model systems and our conclusions regarding correlations between catalytic performance and electrical properties of oxide catalysts.

\section{Experimental}

Preparation of molybdenum oxide nitride

Molybdenum oxide nitride (in the following denoted as $\left.\mathrm{Mo}(\mathrm{O}, \mathrm{N})_{3}\right)$ was prepared by reaction of gaseous ammonia with commercial $\alpha-\mathrm{MoO}_{3}$ (Chempur). Ammonolysis was performed in a conventional tube furnace using a 


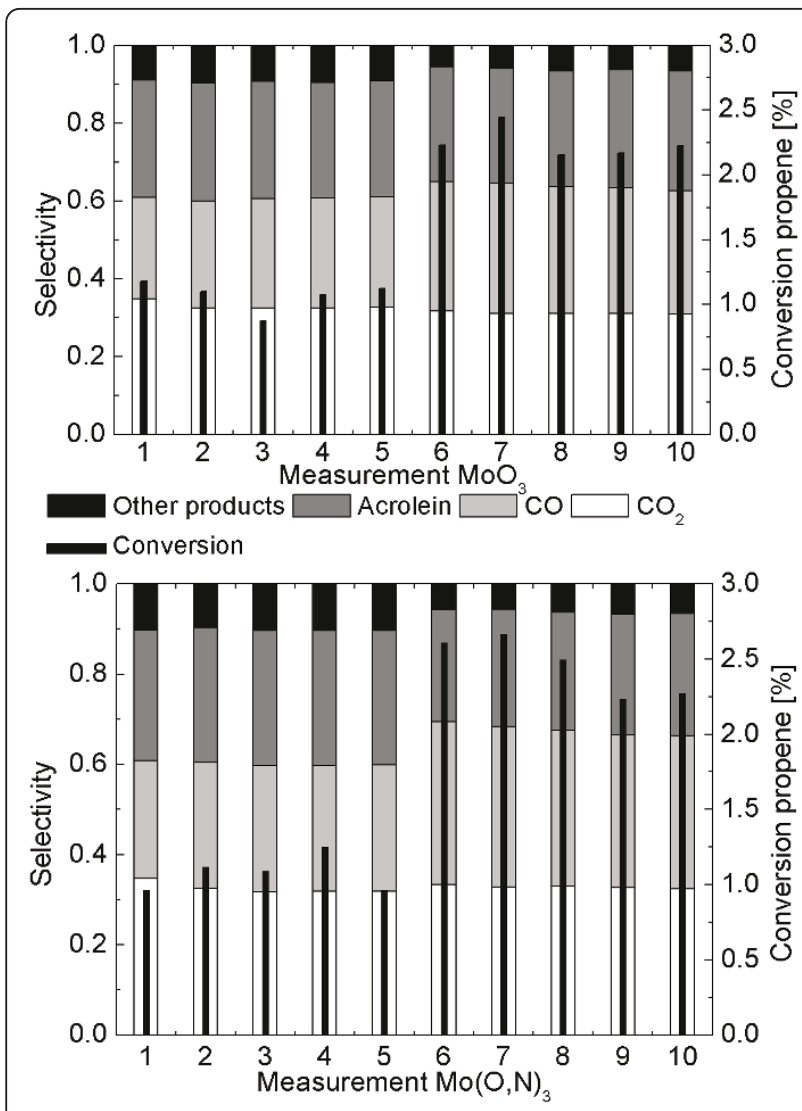

Figure 11 Propene conversion and selectivity of $\alpha-\mathrm{MoO}_{3}$ (top) und $\mathrm{Mo}(\mathrm{O}, \mathrm{N})_{3}$ (bottom) in 5\% propene and $5 \%$ oxygen at 655 $\mathrm{K}$ (measurements 1-5) and $700 \mathrm{~K}$ (measurements 6-10).

silica tube and direct gas supply[23]. After drying at $383 \mathrm{~K}$ in air, $\alpha-\mathrm{MoO}_{3}$ was reacted to $\mathrm{Mo}(\mathrm{O}, \mathrm{N})_{3}$ at 548 $\mathrm{K}$ with an $\mathrm{NH}_{3}$ flow of $10 \mathrm{l} / \mathrm{h}$ for $10 \mathrm{~h}$. These particular conditions had been optimized in respect to a maximum concentration of incorporated nitrogen in $\mathrm{MoO}_{3}$ without a detectable amount of rutile-type $\mathrm{MoO}_{2}$ or $\mathrm{Mo}(\mathrm{O}, \mathrm{N})_{2}$. Increasing the temperature, the presence of such phases was clearly detected using X-ray powder diffraction. With decreasing temperature the nitrogen content of the $\mathrm{MoO}_{3}$ phase strongly decreased. Quantitative nitrogen/oxygen analysis was carried out using the well-established hot gas extraction method (LECO TC-300/EF-300 N/O analyzer). At this procedure the samples were heated under flowing helium in a graphite crucible up to about $2700{ }^{\circ} \mathrm{C}$. Oxygen was determined as $\mathrm{CO}_{2}$ by IR spectroscopy, the amount of nitrogen as $\mathrm{N}_{2}$ gas by heat conductivity measurements of the nitrogen/helium gas. Such measurements resulted in a nitrogen content of $0.41( \pm 0.01)$ wt- $\%$ for the sample used in this work. Hot gas extraction, however, does not permit to study the nitrogen content of the material in situ under catalysis or oxidation-reduction conditions.

\section{Diffuse reflectance UV-Vis spectroscopy}

A JASCO V-670 double beam spectrometer was used for DR-UV-Vis measurements. Ex situ spectra were recorded in a $\mathrm{BaSO}_{4}$ coated integration sphere in a wavelength range from 200 to $2000 \mathrm{~nm}$ and a scanning speed of $40 \mathrm{~nm} / \mathrm{min}$. In situ measurements used a "Praying Mantis" set-up (Harrick) at a scanning speed of $200 \mathrm{~nm} / \mathrm{min}$ in a range from 220 to $900 \mathrm{~nm}$ under catalytic (5\% propene and $5 \% \mathrm{O}_{2}$ in $\mathrm{He}$ ) or reducing (5\% propene in $\mathrm{He}$ ) reaction conditions.

\section{On-line gas phase analysis}

Quantitative catalysis measurements were performed using an online gas chromatography system (Varian CP3800) and a non-calibrated mass spectrometer (Pfeiffer Omnistar). Hydrocarbons and oxygenated reaction products were analyzed using a Deans switch consisting of a carbowax capillary column connected to a AL2O3/ MAPD column or a fused silica restriction $(25 \mathrm{~m} * 0.32$ $\mathrm{mm}$ each), and flame ionization detectors. Reactant gas flow rates of oxygen, propene, and Helium were adjusted with separate mass flow controllers to a total flow of $40 \mathrm{ml} / \mathrm{min}$. A mixture of $5 \%$ propene and $5 \%$ oxygen in helium was used for catalytic testing in the temperature range from $300 \mathrm{~K}$ to $748 \mathrm{~K}$. All lines and valves were preheated to $473 \mathrm{~K}$.

\section{Powder X-ray diffraction}

Ex situ XRD measurements were conducted on an X'Pert PRO MPD diffractometer (Panalytical, $\theta-\theta$ geometry) using $\mathrm{Cu} \mathrm{K}_{\alpha}$ radiation and a solid-state multiplechannel detector. Wide angle XRD scans were collected in reflection mode using a silicon sample holder. In situ XRD experiments were performed in $\theta-\theta$ geometry on a STOE diffractometer ( $\mathrm{Cu} \mathrm{K} \mathrm{K}_{\alpha}$-radiation) equipped with a PARR reaction chamber. Temperature-programmed experiments were conducted in a range from $473 \mathrm{~K}$ to $773 \mathrm{~K}$ in steps of $25 \mathrm{~K}$ and an effective heating rate of $0.32 \mathrm{~K} / \mathrm{min}\left(2 \theta\right.$ range from $10^{\circ}$ to $\left.42^{\circ}\right)$. Measuring time per XRD scan amounted to about 2 hours. The gasphase composition at the cell outlet was analyzed online with a mass spectrometer (Pfeiffer Omnistar).

\section{X-ray absorption spectroscopy (XAS)}

In situ transmission XAS spectra were measured at the Mo K edge $(20.0 \mathrm{keV})$ at beamline X1 at the Hamburg Synchrotron Radiation Laboratory, HASYLAB, using a suitable in situ cell [21]. Samples were pressed to pellets with a diameter of $5 \mathrm{~mm}$ ( $7 \mathrm{mg}$ with $30 \mathrm{mg}$ boron nitride). EXAFS spectra at the Mo $\mathrm{K}$ edge in the $\mathrm{k}$ space up to $14 \AA^{-1}$ were collected in $\sim 4$ min. Temperatureprogrammed reduction was conducted in $5 \%$ propene and $\mathrm{He}$ (total flow of $40 \mathrm{ml} / \mathrm{min}$ ) in a temperature range from $293 \mathrm{~K}$ to $773 \mathrm{~K}$ at a heating rate of $5 \mathrm{~K} / \mathrm{min}$. 
Reaction tests were performed in 5\% propene and 5\% $\mathrm{O}_{2}$ in $\mathrm{He}$ in the temperature range from $293 \mathrm{~K}$ to $723 \mathrm{~K}$ ( $5 \mathrm{~K} / \mathrm{min}$, total flow $40 \mathrm{ml} / \mathrm{min}$ ). The gas atmosphere was analyzed using a non-calibrated mass spectrometer in a multiple ion detection mode (Pfeiffer Omnistar).

$\mathrm{X}$-ray absorption fine structure (XAFS) analysis was performed using the software package WinXAS v3.2 [24]. Linear polynomials and $3^{\text {rd }}$ degree polynomials were fitted to the pre-edge and post-edge region of an absorption spectrum for background subtraction and normalization, respectively. The extended X-ray absorption fine structure (EXAFS) $\chi(\mathrm{k})$ was extracted by using cubic splines to obtain a smooth atomic background $\mu_{O}$ (k). The FT $\left(\chi(\mathrm{k})^{*} \mathrm{k}^{3}\right)$, often referred to as pseudo radial distribution function, was calculated by Fourier transforming the $\mathrm{k}^{3}$ weighted experimental $\chi(\mathrm{k})$ function, multiplied by a Bessel window, into the $\mathrm{R}$ space.

\section{Impedance spectroscopy}

Impedance of molybdenum oxides and oxide nitrides was obtained by measuring the magnitude $|Z|$ and the phase $\phi$ of an alternating current as a response of an applied alternating potential (impedance analyzer N4L: IAI+PSM1735). From that the real part $Z^{\prime}$ and imaginary part Z" of the complex impedance was calculated. The impedance was measured as a function of frequency $(200 \mathrm{kHz}-0.1 \mathrm{~Hz})$ and temperature $\left(\alpha-\mathrm{MoO}_{3}: 527 \mathrm{~K}\right.$ $\left.848 \mathrm{~K}, \mathrm{Mo}(\mathrm{O}, \mathrm{N})_{3}: 306 \mathrm{~K}-449 \mathrm{~K}\right)$. Oxides and oxide nitride samples were pressed to pellets with a diameter of $15 \mathrm{~mm}$ (1.5 g initial weight, $7.5 \mathrm{kPa}$ pressure) and placed between two $\mathrm{Pt}$ disc electrodes for impedance measurements.

\section{Acknowledgements}

The Hamburg Synchrotron Radiation Laboratory, HASYLAB, is acknowledged for providing beamtime for this work. A. Stys and A. Walter are acknowledged for contributing to the materials characterization. The authors are grateful to the Deutsche Forschungsgemeinschaft, DFG (Cluster of Excellence "Unifying Concepts in Catalysis") for financial support.

\section{Authors' contributions}

SK participated in sample characterization and data analysis, and drafted the manuscript. PSZ and AHPH participated in impedance and XAFS data measurements, respectively. $\mathrm{MH}$ and $\mathrm{ML}$ performed the sample preparation and nitrogen analysis. TR participated in sample characterization and data analysis, and design and coordination of the study. All authors read and approved the final manuscript.

\section{Competing interests}

The author declares that they have no competing interests.

Received: 7 April 2011 Accepted: 15 July 2011 Published: 15 July 2011

\section{References}

1. Grzybowska-Swierkosz B: Thirty years in selective oxidation on oxides: what have we learned? Top Catal 2000, 11/12:23-42.

2. Grasselli RK: Advances and future trends in selectiv oxidation and ammoxidation catalysis. Catal Today 1999, 49:141-153.
3. Haber J, Lalik E: Catalytic properties of MoO3 revisited. Catal Today 1997, 33:119-137.

4. Mars $P$, van Krevelen DW: Oxidations carried out by means of vanadium oxide catalysts. Chem Ing Sci 1954, 3:41-59.

5. Krenze LD, Keulks GW: The catalytic oxidation of propylene: VI. Mechanistic studies utilizing isotopic tracers. J Catal 1980, 61:316-325

6. Ueda W, Moro-Oka Y, Ikawa T: Study of ternary-component bismuth molybdate catalysts by 1802 tracer in the oxidation of propylene to acrolein. J Catal 1981, 70:409-417.

7. Grasselli RK: Fundamental principles of selective heterogeneous oxidation catalysis. Top Catal 2002, 21:79-88.

8. Ushikubo T, Oshima K, Kayou A, Hatano M: Ammoxidation of propane over Mo-V-Nb-Te mixed oxide catalysts. Stud Surf Sci Catal 1997, 112:473-480.

9. Grasselli RK, Buttrey DJ, DeSanto P Jr, Burrington JD, Lugmair CG, Volpe AF, Weingand T: Active centers in Mo-V-Nb-Te-Ox (amm)oxidation catalysts. Catal Today 2004, 91-92:251-258.

10. Pfisterer D, Sann J, Hofmann DM, Plana M, Neumann A, Lerch M, Meyer BK: Incorporation of nitrogen acceptors in ZnO powder. Phys Stat Sol B 2006, 243(1):1-3.

11. Lee JS, Lerch M, Maier J: Nitrogen-doped zirconia: A comparison with cation stabilized zirconia. J Solid State Chem 2006, 179(1):270-277.

12. Schilling $H$, Lerch $M$, Boerger $A$, Becker $K D$, Wolff $H$, Dronskowski $R$, Bredow T, Tovar M, Baehtz C: A new anatase-type phase in the system Mg-Ta-O-N. J Solid State Chem 2006, 179(8):2416-2425.

13. Nakhal S, Hermes W, Ressler T, Pöttgen R, Lerch M: Synthesis, crystal structure and magnetic properties of bixbyite-type vanadium oxide nitrides. Z Naturf B 2009, 64(3):281-286.

14. Soerijanto $H$, Rödel $C$, Wild $U$, Lerch $M$, Schomäcker $R$, Schlögl R, Ressler $T$ : The impact of nitrogen mobility on the activity of zirconium oxynitride catalysts for ammonia decomposition. J Catal 2007, 250:19-24.

15. Young RA: The Rietveld Method. In IUCr Monographs on Crystallography. Volume 5. Oxford: Oxford University Press; 1993.

16. Ressler T, Wienold J, Jentorf RE, Neisius T: Bulk Structural Investigation of the Reduction of $\mathrm{MoO} 3$ with Propene and the Oxidation of $\mathrm{MoO} 2$ with Oxygen. J Catal 2002, 210:67-83.

17. Dieterle M, Weinberg G, Mestl G: Raman spectroscopy of molybdenum oxides Part I. Structural characterization of oxygen defects in MoO3-x by DR UV/VIS, Raman spectroscopy and X-ray diffraction. Phys Chem Chem Phys 2002, 4:812-821.

18. Lerch M, Janek J, Becker KD, Berendts S, Boysen H, Bredow T, Dronskowski R, Ebbinghaus S, Kilo M, Lumey MW, Martin M, Reimann C, Schweda E, Valov I, Wiemhöfer HD: Oxide nitrides: From oxides to solids with mobile nitrogen ions. Progress in Solid State Chemistry 2009, 37:81-131.

19. Ressler T, Wienold J, Jentoft RE, Girgsdies F: Evolution of Defects in the Bulk Structure of $\mathrm{MoO} 3$ During the Catalytic Oxidation of Propene. Eur J Inorg Chem 2003, 2:301-321.

20. Ressler T, Wienold J, Jentoft RE, Timpe O, Neisius T: Solid state kinetics of the oxidation of $\mathrm{MoO} 2$ investigated by time-resolved X-ray absorption spectroscopy. Solid State Comm 2001, 119:169-174.

21. Ressler T, Jentoft RE, Wienold J, Günter MM, Timpe O: In Situ XAS and XRD Studies on the Formation of Mo Suboxides during Reduction of MoO3. J Phys Chem B 2000, 104:6360-6370.

22. Sunu S, Prabhu E, Jayaraman V, Gnanasekar Kl, Seshagiri TK, Gnanasekaran T: Electrical conductivity and gas sensing properties of MoO3. Sensors and Actuators B 2004, 101:161-174.

23. Berendts S, Huber M, Weiß M, Lehmann M, Ressler T, Lerch M: Synthese, Charakterisierung und Reaktivität von Molybdänoxidnitriden. Z Anorg Allg Chem 2008, 634:2029.

24. Ressler T: WinXAS: a Program for X-ray Absorption Spectroscopy Data Analysis under MS-Windows. J Synch Rad 1998, 5:118-122.

doi:10.1186/1752-153X-5-42

Cite this article as: Kühn et al:: Structure and properties of molybdenum oxide nitrides as model systems for selective oxidation catalysts.

Chemistry Central Journal 2011 5:42. 